\title{
MONTEIRO LOBATO: O PERFIL DE UM INTELECTUAL MODERNO
}

Dilma Castelo Branco Diniz*

ABSTRACT:

The aim of this essay is to discuss the socio-political significance of the life and writings of José Bento Monteiro Lobato, an intellectual who proposed a nationalistic project for the modernization of Brazil.

KEY-WORDS: Project; Modernization; Intellectual Profile.

Na história da literatura brasileira, não se costuma associar o adjetivo moderno ao nome de Monteiro Lobato. Esse fato se deve, sobretudo, à posição assumida pelo escritor em seu célebre artigo "Paranóia ou mistificação?", no qual se posicionou contra a arte moderna, apresentada por Anita Malfatti na famosa exposição de dezembro de 1917.

Entretanto, ao examinar a vida e a obra desse intelectual preocupado com os problemas brasileiros, e tomando por base as características pragmáticas de sua personalidade de homem de ação, pode-se perceber que Lobato idealizou e tentou implementar um projeto para modernizar o Brasil - um projeto que seria, ao mesmo tempo, nacional e popular. E o que tentarei mostrar neste ensaio.

Na antropologia moderna, o conceito de projeto parece particularmente fértil para tratar de trajetórias individuais. Nos termos de Alfred Schutz projeto é a "conduta organizada para atingir finalidades específicas" ( SCHUTZ apud VELHO, 1994:40). É importante também lembrar o conceito histórico de modernização, que foi definido por S. N. Eisenstadt como

* Doutora em Literatura Comparada, 1997. 


\section{EM TESE}

Belo Horizonte, V. 2, p. I - I64, Dez. 1998

0 processo de mudança para os tipos de sistemas sociais, econômicos e políticos que se desenvolveram na Europa ocidental e América do Norte, entre os séculos XVII e XIX, espalhando-se, então, por outros países europeus e, nos séculos $X I X$ e $X X$, pelos continentes sul-americano, asiático e africano. (EISENSDADT, 1969:11)

Essa definição revela que, numa certa etapa da história e numa região geográfica específica - a Europa Ocidental da Ilustração - desenvolveram-se processos de racionalização que provocaram inovações nos sistemas sociais, econômicos e políticos, destruindo as bases da sociedade tradicional. Inovações essas que se espalharam, pouco a pouco, pelo mundo inteiro.

Influenciado por essas noções de racionalização e acreditando no poder das idéias, Monteiro Lobato utilizará de sua pena e de sua atuação para modernizar o Brasil. Homem extremamente curioso, irrequieto e profundamente interessado nos diversos aspectos da vida social brasileira, não se contentou em ser apenas um escritor. Foi também crítico de arte, tradutor, editor, jornalista e publicista. Tornou-se também um conhecido homem de negócios, ao criar companhias de ferro e de petróleo. É considerado ainda o criador de nossa literatura infantil. Em todas essas facetas de sua atuação, o escritor despendeu grandes esforços para implementar o seu projeto modernizador.

A base do projeto lobatiano está diretamente ligada à tomada de consciência do escritor, ao perceber a miséria do interior brasileiro, e ao desejo de se tornar um agente de mudanças no país.

Quando em 1911 morre seu avô, o Visconde de Tremembé, Lobato recebe de herança a fazenda São José, no Vale do Paraíba do Sul, uma enorme propriedade encravada na Serra da Mantiqueira, em São Paulo. E é na fazenda, como proprietário rural, que Lobato vai prestar mais atenção aos caipiras e desse aprendizado criará o tipo que o consagrará definitivamente na vida literária: o Jeca Tatu, um dos personagens mais famosos de nossa literatura, que se popularizou de tal maneira que se transformou em substantivo comum e assim foi dicionarizado.

Cassiano Nunes observa, com muita propriedade, que é "realmente singular" que um dos personagens mais famosos de nossa literatura 
não tenha provindo das regiões mais puras da ficção (romance, novela, conto, poesia épica ou teatro), porém do chão mais seco da prosa crítica, da área mais sóbria e prática do artigo de jornal ou pequeno ensaio. ( NUNES, 1992)

De fato, é importante reiterar que "Velha Praga", um verdadeiro ensaio ecológico, um grito de alerta do fazendeiro Monteiro Lobato diante das queimadas tão freqüentes no nosso interior, aparece publicado no jornal 0 Estado de São Paulo em 12 de novembro de 1914, com o tom das cartas de leitores que se dirigem aos jornais transmitindo, muitas vezes, contundentemente, queixas ou reclamações. Jeca Tatu, que foi delineado em "Velha Praga", será retomado e fixado brilhantemente, num novo artigo, "Urupês", publicado no mesmo jornal, em 23 de dezembro do mesmo ano.

"Urupês" e "Velha Praga" constituem, realmente, o que Cassiano Nunes chama de o "nódulo fundamental" (NUNES, 1992) da obra literária de Monteiro Lobato. E acredito que também seja o ponto de partida do seu projeto de modernizar - Brasil, porque o seu patriotismo estava estreitamente ligado ao conhecimento da realidade brasileira.

Os traços constitutivos de seu projeto, no entanto, só aparecem claramente, na sua faceta de crítico de arte, ao lutar por uma arte nacional e popular. Num artigo intitulado "A caricatura no Brasil", publicado em 0 Estado de São Paulo em 21 de janeiro de 1915, Lobato defende uma visão de arte que despreza a produção e o gosto da nossa elite e preconiza uma arte popular, que vê no "povo" a única fonte de surgimento de uma arte genuinamente brasileira. Para uma melhor compreensão das preocupações estéticas lobatianas, naquela época, convém analisar atentamente os primeiros artigos reunidos no volume Idéias de Jeca Tatu, em 1919, que podem ser considerados como testemunho de seu posicionamento estético em defesa de uma arte brasileira.

Lobato costuma ser visto na história da literatura brasileira como alguém totalmente alheio ao movimento modernista. Entretanto, somente sua atuação no meio editorial já desmente esse fato. Como editor, Lobato continuaria a implementar o seu projeto modernizador. Em meados de 1917, Monteiro Lobato vende sua fazenda e se transfere para a cidade de São Paulo. Logo depois, compra a 
Revista do Brasil, transformando-a numa editora que vai "revolucionar o panorama do livro e da leitura no Brasi1". ( LIMA, 1985:45)

Sua primeira atitude revolucionária como editor seria enfrentar a questão da distribuição dos livros. É que, naquela época, havia em todo o Brasil somente umas quarenta livrarias. Para solucionar esse problema, Lobato escreve aos numerosos agentes do correio, espalhados pelo país, pedindo a indicação de firmas ou casas que pudessem receber e vender uma mercadoria chamada "livro". Redigiu então uma circular que iria constituir a base da indústria editorial brasileira:

"Vossa Senhoria tem o seu negócio montado e quanto mais coisas vender maior será o lucro. Quer vender tambêm uma coisa chamada 'livro'? Vossa Senhoria não precisa inteirar-se do que essa coisa é. É um artigo comercial como qualquer outro, batata, querosene ou bacalhau. E como Vossa Senhoria receberá esse artigo em consignação, não perderá coisa alguma no que propomos. Se vender os tais 'livros', terá uma comissão de $30 \%$, se não vendê-los, no-los devolverá pelo correio, com o porte por nossa conta. Responda se topa ou não topa". Todos toparam e nós passamos dos quarenta vendedores, que eram as livrarias, para mil e duzentos "pontos de venda", fosse livraria ou açougue. (LOBATO, 1950, v. XIII:213)

0 público recebeu muito bem essas mudanças e as edições, que antes eram de 400 ou 500 volumes e muito espaçadas, imediatamente pularam para 3.000 exemplares em média e começaram a sair várias por semana.

Como escritor-editor foi também pioneiro, ao pôr em prática uma concepção moderna do escrever, que considerava o leitor não só como virtualidade presente no texto, mas como um território a ser conquistado, procurando criar mecanismos de circulação da obra. Nesse sentido, a criação da literatura infantil brasileira acrescenta-1he mais um título de modernidade: com essa nova modalidade de expressão literária, Lobato amplia e diversifica notadamente o seu público. Ao tornar viável a circulação do texto literário no Brasil, Lobato sentiu a necessidade de inserir a indústria editorial em premissas capitalistas - fato que, dada a perspectiva dos anos vinte, constituía, sem dúvida, um processo de modernização.

A inserção de Lobato na história da literatura brasileira dá-se, portanto, num plano mais complexo do que o de um simples escritor. Sua ação 
editorial - primeiro na Revista do Brasil, depois na Monteiro Lobato \& Cia e, mais tarde, na Companhia Editora Nacional - constitui outra manifestação de um projeto literário igualmente engajado, mas agora perfeitamente sintonizado com a modernidade e o cosmopolitismo que influenciaram tantos pronunciamentos da geração de 22 .

As mesmas características de "arte brasileira e popular" que Lobato preconiza, sobretudo para as artes plásticas (inclusive a arquitetura), encontramse presentes em sua literatura para adultos. Seus contos são todos narrativas populares que retratam os nossos problemas. No período imediatamente anterior à Semana de Arte Moderna, com seus ensaios e contos Monteiro Lobato assume a responsabilidade da denúncia, ao lançar a personagem polêmica do Jeca Tatu figura simbólica do marasmo e da indigência da vida nacional, que vem estabelecer uma ligação entre a literatura e as questões sociais. Urupês não se limitou ao sucesso literário, mas provocou reações politicas e levantou questões de cunho sociológico.

Mas foi como escritor para crianças que Lobato alcançou a celebridade. A história de Dona Benta, proprietária do Sítio, aquela velha de mais de sessenta anos, óculos de ouro na ponta do nariz, que mora com a mais encantadora das netas, Lúcia, conhecida por Narizinho, e uma cozinheira antiga e fiel, a tia Nastácia, marcou a imaginação de gerações e gerações de brasileiros.

Com a criação do Sítio do Picapau Amarelo, Monteiro Lobato inaugurou nossa literatura infantil, "gênero marcadamente moderno", pois o aparecimento de livros para crianças pressupõe uma organização social moderna, em que as crianças são vistas como "consumidoras exigentes de uma literatura diferente da destinada aos adultos". (LAJOLO, 1985:49)

Torna-se interessante assinalar que seus livros para crianças são também fruto de suas preocupações nacionalistas. Ao reconhecer a pobreza e o mau gosto de nossa literatura infanti1, revela ao amigo Godofredo Rangel, em 1916:

As făbulas em português que conheço, em geral traduções de La Fontaine, são pequenas moitas de amora do mato - espinhentas e impenetráveis. Que é que as nossas crianças podem ler? Não vejo nada [...]. 


\section{EM TESE}

Belo Horizonte, V. 2, p. I - 164, Dez. 1998

Ora um fabulário nosso, com bichos daqui em vez dos exóticos, se for feito com arte e talento dará coisa preciosa [...]. Fábulas assim seriam o começo da literatura que nos falta? (LOBATO, 1950, v. XII:104)

Havia uma preocupação pedagógica por trás dessas considerações. Lobato observara a reação de seus filhos às histórias contadas pela esposa: percebeu que os meninos eram capazes de recontá-las aos amigos, sem se preocupar com as moralidades. "A moralidade nos fica no subconsciente para ir se revelando mais tarde, à medida que progredimos em compreensão" (LOBATO, 1950,v. XII:104). Daí surgiu-1he a idéia de nacionalizar as velhas fábulas de Esopo e La Fontaine, mexendo nas moralidades, o que foi feito em Fábulas, publicado em 1922.

Sua idéia de construir uma literatura para crianças insere-se, pois, num projeto maior: a tarefa de formar uma nova mentalidade nacional. Essa intenção, esboçada em seus primeiros livros (1921-1922), desenvolve-se plenamente, nos anos 30 e 40, período em que escreveu definitivamente sua obra para crianças.

A saga lobatiana do Picapau Amarelo constitui ainda, em sua formulação básica, uma utopia que muito se assemelha à utopia proposta por 0swald de Andrade. 0 sítio de Dona Benta se mostra, realmente, como um "matriarcado de Pindorama", um espaço livre e harmônico, isento da repressão e aberto à atividade criadora e lúdica - um espaço da cultura antropofágica, um espaço do ócio e não do negócio, como na sociedade patriarcal. Mas essa visão não implica um simples retorno, pois o sitio convive com a tecnologia moderna e seus habitantes chegam à condição de "bárbaros tecnicizados". Tanto para Lobato como para Oswald, o Brasil seria, por excelência, o país da utopia, desde que se atualizasse pela industrialização. Na verdade, foi Monteiro Lobato que realizou, com o Sítio do Picapau Amarelo, a utopia oswaldiana do "Matriarcado de Pindorama e o bárbaro tecnicizado". Esse fato também atesta que Monteiro Lobato se encontra mais perto dos escritores modernistas do que normalmente se apregoa.

A sua faceta de jornalista/publicista marcou momentos críticos da nossa história. Ao participar da campanha pela saúde, com o Jeca Tatuzinho, Lobato revela-se um pioneiro e um inovador da publicidade em nosso país. A história intitulada por Lobato de "Jeca Tatu: A Ressurreição" (e incorporada ao 
final do livro Problema Vital) foi adotada pelo Laboratório Fontoura, para propaganda de seus produtos. Recebeu o nome de Jeca Tatuzinho, não só porque era uma história dedicada à infância rural brasileira, como pelo pequeno formato das edições distribuídas. Nela, o Jeca passa de seu estado de apatia a um triunfo inesperado, chegando a ser um fazendeiro saudável e rico, depois de ter tomado o remédio salvador. Mas Lobato não se restringe a esses dois retratos do Jeca. Nos anos quarenta, o caboclo ressurgirá na pena lobatiana, no folheto Zé Brasil, que foi usado para a propaganda da reforma agrária e do partido comunista de Luîs Carlos Prestes.

Monteiro Lobato foi ainda um homem de negócios, tendo criado companhias de ferro e de petróleo. Nessa época, Lobato estava inteiramente convencido de que só a industrialização poderia resolver os problemas brasileiros. Mas havia uma politica centralizadora e corporativista no Brasil, sobretudo depois do Estado Novo, quando se reduziu, drasticamente, a esfera propriamente politica no interior da sociedade. Interessava ao governo - até por uma questão de aumento de poder - a nacionalização dos recursos minerais. É preciso também lembrar que, ao contrário de vários escritores modernistas que acabaram participando do governo autoritário de Getúlio Vargas, Lobato não aceitou as ofertas que the foram feitas pelo Ditador, chegando, com essa atitude, até à prisão. Foi certamente por isso que Carlos Drummond de Andrade chamou-o de "herói civil da literatura brasileira" (ANDRADE, 1948), em artigo publicado logo depois de sua morte.

Apesar de não aceitar certos postulados modernistas, Monteiro Lobato exerceu uma atuação importantíssima na base do nosso Modernismo e, com sua ação político-literária modernizadora, passou de simples escritor a grande personagem de nossa história.

Enfim, considero que o humor de Lobato foi não só sua válvula de escape, no instante das derrotas e do ressentimento, mas também um atributo valoroso, significando criatividade, transcendência e sabedoria. Segundo Cassiano Nunes, Lobato "foi salvo do desespero, redimido do rancor, por essa qualidade artística equilibradora e paradoxalmente construtiva". (NUNES, 1981) 


\title{
EM TESE
}

Belo Horizonte, V. 2, p. 1 - 164, Dez. 1998

Certa vez, no fim de sua vida, Lobato escreveu esta carta a um editor que the havia pedido dados pessoais, para serem transcritos num dicionário dos grandes homens do Brasil:

\author{
São Paulo, 10-5-1947 \\ Prezado Sr. J. Henriques,
}

Recebi sua carta de 2 deste, na qual me pede um verdadeiro compte-rendu da minha vida em benefício da obra a publicar-se OS GRANDES VULTOS DO BRASIL. Respondo declarando que em sã consciência não posso atendê-10; mas se por acaso a Empresa Histórica Nacional houver por bem, um dia, dar a público uma obra que muitíssima falta nos faz, OS GRANDES IDIOTAS DO BRASIL, terei o máximo gosto em responder a todas as perguntas e até tomarei a liberdade de insistir para que me coloquem num dos primeiros lugares. Com a maior estima e sensibilizadíssimo pela honra que me fez considerando-me "vulto", assinome cordialmente

Monteiro Lobato (In NUNES, 1981:57-8)

RESUMO:

Este trabalho pretende ser uma leitura concisa da vida e da obra de José Bento Monteiro Lobato, enquanto um intelectual que formulou e tentou implementar um projeto de modernização do Brasil - um projeto que era ao mesmo tempo nacional e popular - com o objetivo de esboçar o seu perfil intelectual.

PALAVRAS CHAVE: Projeto; Modernização; Perfil intelectual. 


\section{REFERÊNCIAS BIBLIOGRÁFICAS}

ANDRADE, Carlos Drummond de. Herói Civil da Literatura. O Jornal, 11 de julho de 1948.

COLEÇÃO GRANDES PERSONAGENS DA NOSSA HISTÓRIA. 4 volumes. São Paulo: Abril Cultural, 1970. Supervisão de Sérgio Buarque de Holanda.

DINIZ, Dilma Castelo Branco. Urupês, de Monteiro Lobato: uma obra de transição. Belo Horizonte: UFMG, 1990. (Dissertação de Mestrado).

- Monteiro Lobato: o perfil de um intelectual moderno. Belo Horizonte: UFMG, 1997 (Tese de Doutorado) .

EISENSTADT, S. N. Modernização: protesto e mudança. Modernização de sociedades tradicionais. Rio de Janeiro: Zahar, 1969.

LAJOLO, Marisa. Monteiro Lobato. A modernidade do contra. São Paulo: Brasiliense, 1985.

LIMA, Yone S. de. A ilustração na produção literāria. São Paulo, década de vinte. São Paulo: Instituto de Estudos Brasileiros / USP, 1985.

LOBATO, José Bento Monteiro. Obras Completas. Literatura Geral. 13 volumes. São Paulo: Editora Brasiliense, 1950. Os volumes 15, 16 e 17 são de 1959 e o 14, de 1964.

- Obra Infantil Completa. 8 volumes. Ilustrações de Manoel Victor Filho. São Paulo: Editora Brasiliense, s.d.

- Jeca Tatuzinho. Ilustrações de K. Wiese. 35. ed. São Paulo: Fontoura, 1973.

- Zé Brasil. Ilustrações de Percy Deanne. Rio de Janeiro: Editorial Vitória, 1947.

- Zé Brasil. Ilustrações de Cândido Portinari. Rio de Janeiro: Calvino Filho, 1948.

NUNES, Cassiano. O patriotismo dificil. A correspondência entre Monteiro Lobato e Arthur Neiva. São Paulo, 1981.

VELHO, Gilberto. Projeto e metamorfose: antropologia das sociedades complexas. Rio de Janeiro: Zahar, 1994. 